\title{
COVID-19, flattening the curve: recommendations towards control and managing a second wave
}

\author{
Iziegbe Fenemigho' ${ }^{1}$, Ewaenosa Ukponmwan', Elizabeth C Nnakwue ${ }^{3}$, Iboro Udoete ${ }^{4}$, Chisom Asuzu ${ }^{5}$, Adeleye \\ Adaralegbe $^{6}$, Utibe Effiong ${ }^{7}$ \\ 1 University of South Wales, Public Health Department, Glyntaff, Pontypridd, United Kingdom, ${ }^{2}$ College of Medicine, University of Benin, Benin, \\ Nigeria, ${ }^{3}$ College of Medicine, University of Ibadan, Ibadan, Nigeria, ${ }^{4}$ All Saints University, Roseau, Dominica, 5 Rutgers, The State University of New \\ Jersey, New Brunswick. New Jersey, United States, ${ }^{6}$ University of Connecticut, Department of Allied Health Sciences, United States, ${ }^{7}$ Central Michigan \\ University, Mount Pleasant, Michigan, United States \\ Keywords: covid-19, contact tracing, infection control, mitigation \\ https://doi.org/10.29392/001c.14151
}

\section{Journal of Global Health Reports}

Vol. 4, 2020

\begin{abstract}
Flattening the coronavirus disease (COVID-19) curve has been one of the most important public health targets since the outbreak of the severe acute respiratory syndrome coronavirus 2 (SARS-CoV-2) worldwide. In this review, we examined measures that were key to flattening the curve in countries that have succeeded in achieving this against other countries. The most consistent factors seen from studies were aggressive testing, contact tracing, social distancing, quarantine measures, and innovative technology. These factors were reported to have helped achieve drop in the number of daily new cases reported. Countries like South Korea and Australia employed extensive testing of their residents as a means of curbing the pandemic and limiting its spread. China and Spain employed tracking software and artificial intelligence (AI) in ensuring that infected individuals remained isolated for the recommended number of days and that close contacts of positive cases were tested and quarantined as well. While efforts towards developing a vaccine are still ongoing, and the possibility of a second wave in many countries, we discussed pertinent public health measures and recommendations.
\end{abstract}

Coronavirus disease (COVID-19) broke out in early December 2019, in Wuhan, China. It was not until late January of 2020 that it became a global pandemic, spreading across neighboring countries and beyond. ${ }^{1}$ For all the infected countries, the goal of containing the virus was to be achieved by flattening the "curve", which simply meant attaining fewer new cases than the previous day. ${ }^{2}$ Flattening the curve became imminent to curtail the spread of the virus so as to reduce the burden on the healthcare system, allowing for better treatment and performance of healthcare workers. ${ }^{3}$

A flattened curve is reflected in the basic reproductive number, known as R0. This represents the number of cases that arise from an index case. An epidemic threshold is reached when $\mathrm{R} 0$ exceeds one. When $\mathrm{R} 0$ is less than 1 it means one infectious case infects less than one person and the epidemic cannot be sustained. Public health measures like social distancing, travel ban, and vaccination will lead to a reduction in $\mathrm{R} 0$ to less than one, manifesting as a flattened curve. ${ }^{4}$

Unlike China, subsequent countries had the advantage of time to formulate strategies to combat this virus. Some countries were proactive in early implementation of these new strategies such as; travel restrictions, social distancing, school closures, public education, lockdown measures, increased screenings, contact testing and tracking, etc. This early implementation paid off as they were quickly able to contain the virus, thereby attaining a flattened curve early.
Other countries that were not as prepared were caught offguard and lagged with their response to the COVID-19 pandemic. ${ }^{5}$ This unpreparedness was also made evident by the increased incidence of cases and morbidity of infected patients in these countries. We highlight these measures that were key to flattening the curve from countries that have succeeded in controlling the COVID-19 pandemic.

\section{AGGRESSIVE TESTING}

Aggressive testing has been shown to be beneficial in countries, which have flattened their curves successfully. In these countries, testing was widespread, involving both symptomatic and asymptomatic people. An example is South Korea, which was very creative with its testing methods. South Korea is one of two countries with initial large outbreaks that managed to flatten its curve in record time. ${ }^{6}$ It rapidly conducted an estimated 15,000 tests per day in the first couple of weeks following the spread of the virus within its borders. It is also one of the pioneer countries to introduce 'drive-thru' clinics and ' $\mathrm{K}$ - walk- thru' services. Through these methods, samples are collected quickly, safely and the risk of transmission among health workers was markedly reduced. ${ }^{7}$ In the drive-through testing, the testee stays inside their car throughout the testing process, and samples are collected through the car window. There is minimal contact between the testee and health care personnel and no need for an extra isolation room. Walkthrough 
testing is performed using the negative pressure booth or the positive pressure booth. The difference between the two depends on the position of the tester relative to the testee. In the negative pressure booth, the testee stays inside the disinfected booth but this scenario is reversed when using the positive pressure booth. Contamination of the booth is prevented in the positive pressure booth, as well as the need to constantly disinfect after every test is done. ${ }^{8}$ South Korea has conducted 885,120 tests as of 30 May, 2020, ${ }^{9}$ bringing it to approximately 17,000 tests per million of its population. This made South Korea flatten its curve without resulting in extreme lockdown measures that most other countries had to result to. ${ }^{10}$

Australia is another country that carried out aggressive testing of its population during the COVID-19 pandemic. In the beginning, only those who had returned from overseas or been in contact with COVID-19 cases were tested. Subsequently, testing expanded to include health workers, aged care workers, those in prison, and those with symptoms or in hot spots. Right now, testing has been made to include even the asymptomatic cases with the aim of recognizing and isolating them on time to limit spread. ${ }^{11}$ As of May 302020 , they had done over 1.4 million tests ${ }^{12}$ bringing it to almost 58,000 tests per million population. When compared with other countries like Brazil who have carried out about 740,000 COVID-19 tests ${ }^{13}$ and bringing it to only about 3000 tests per million population, we can deduce that extensive testing amongst not just symptomatic and exposed persons, but also testing asymptomatic people will invariably reduce the spread of the virus.

\section{EARLY RESTRICTION}

Infection by the severe acute respiratory syndrome coronavirus 2 (SARS COV-2) is mainly spread by the movement of persons. Unfortunately, the world being a global village with ease of travel across continents, only fostered the spread of this pandemic. Countries that were prompt in taking action by placing travel restrictions and strict quarantine and lockdown measures have had an edge in the successful containment of the virus. ${ }^{5}$ New Zealand and Australia were at the forefront in taking such measures.

New Zealand has been praised by the world for being quick to act. Prime Minister Jacinda Arden was quick to close its borders on February 3, 2020 and implement a nationwide lockdown by March 19,2020, with just 102 cases and barely a month after the first case in the country. New Zealand carried out an elimination strategy, one not feasible by most countries. A decision they were confident enough to implement due to an early action against the pandemic. A multilevel COVID-19 alert system was activated on March 21,2020 with an initial level 2 and elevated to a level 3 (movement restriction) on March 23, 2020. This metamorphosed into a strict lockdown by March 25,2020, the most stringent by far when compared to other nations dealing with the initial clusters of COVID-19. This was in place for a month and on 28 April, 2020, New Zealand reverted to level three, declaring an early victory over the virus. ${ }^{14}$ As a result of this elimination strategy, New Zealand has consistently had single-digit cases, often having no case per day, successfully curbing viral propagation and momentum. ${ }^{15}$ Countries like the United States only implemented extensive travel restrictions late around mid March 2020. ${ }^{16}$ Although there was some semblance of random screening at the airports with temperature checks, prior to this, strict quarantine measures for all passengers who arrived were not instituted. ${ }^{17,18}$

Similarly, Thailand was prompt with its measures to curb the importation of the disease at its borders. Screening for COVID-19 at Thai international airports began on Jan 3 . This was before most countries began screening and this singular action may have resulted in a vast reduction of imported cases. Even though Thailand did not issue a total ban on all travel into Thailand until early April 2020, the Thai airport Authority was quick to implement compulsory quarantine without exceptions for anyone traveling into the country. Travelers also had to show a travel certificate of wellness, gotten not later than 72 hours before boarding. There was a designated location for quarantine which held travelers for 14 days before being allowed to the community. ${ }^{19}$

Unlike New Zealand and Thailand, Sweden used an unconventional approach to containing the virus spread. Unlike other neighboring Scandinavian and European nations, Sweden did not enforce strict lockdown due to the fear of economic downturn due to the pandemic. ${ }^{20}$ Early in March, while other countries enacted full restrictions to movements, Sweden's restrictions were only limited to the gathering of more than 550 people and some schools. Playgrounds, stores, offices, restaurants, pubs, and most schools were permitted to operate by the government, and citizens were encouraged to social distance voluntarily. This relaxed restriction policy by the government of Sweden resulted in a higher death rate per million people, $40 \%$ more than the United States (with the highest number of death) and at least $600 \%$ more than any of the neighboring Scandinavian nations that enforced early and stricter measures. ${ }^{21}$ Sweden's late and unorthodox lockdown measures led to a longer time to achieve a flattened COVID-19 curve compared to countries like Denmark that were quick to enact strict measures and able to flatten the curve in under four weeks. ${ }^{22}$ Similarly, a study reported that countries that initiated early lockdown (e.g., New Zealand, Hungary) fared much better than those that began lockdown after a high infection rate (e.g. Spain, Italy). A good measure of an effective early restriction is, therefore, reduction in the rates of infection and death four weeks post-baseline infection as evidenced from various countries. ${ }^{23}$

\section{CONTACT TRACING}

Contact tracing in public health involves locating persons with possible exposure to an infection and gathering information about other possible exposures stemming from the index case. In an extremely contagious disease like COVID-19, this mostly involves an extensive and resourceintensive search of all exposures irrespective of the presence or absence of symptomatology. 24

For instance, Thailand carried out an extensive tracing of contacts. This was feasible due to a robust grassroots volunteer system of about 1 million individuals in strength that was mobilized to investigate, track, and notify contacts of 


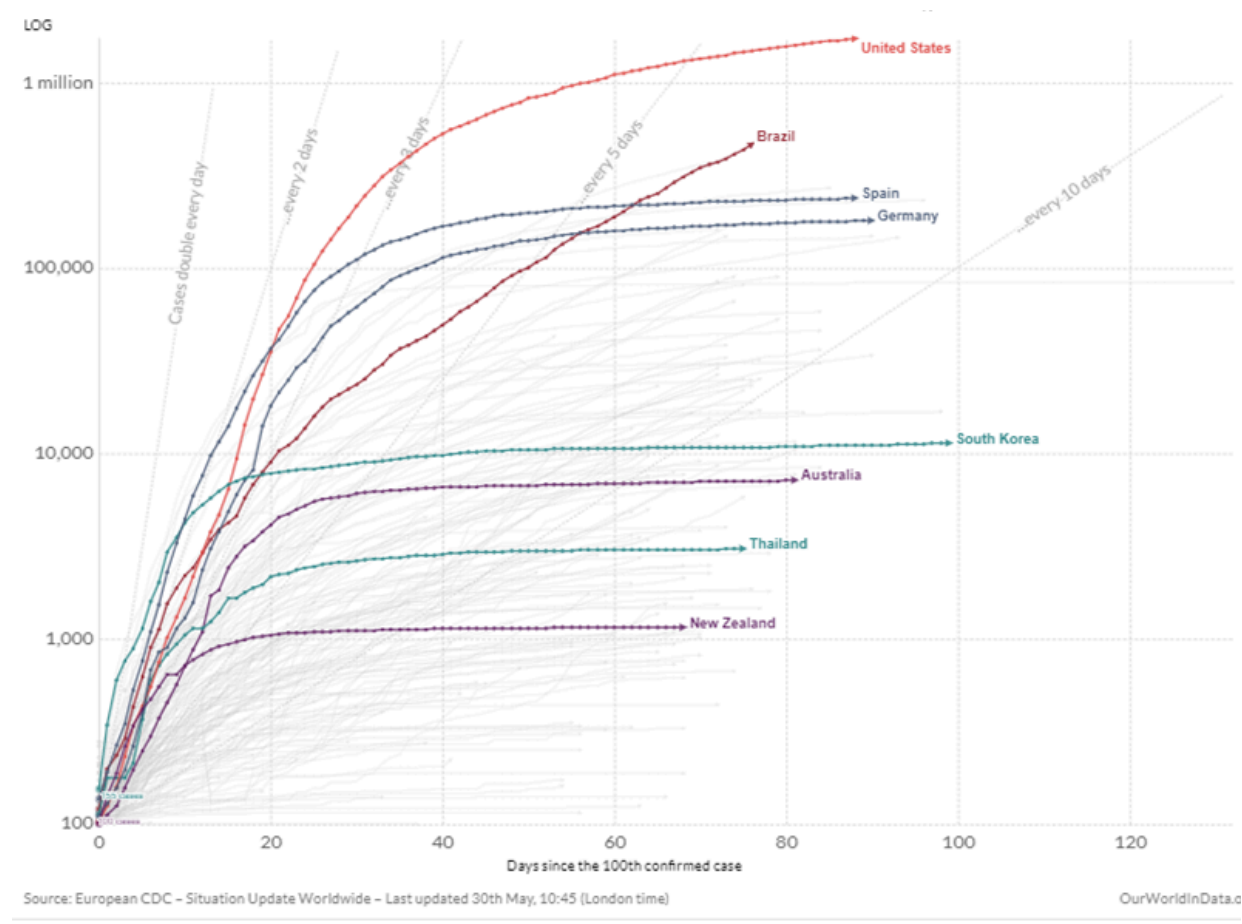

Figure 1: Total confirmed COVID-19 cases, Jan 21 - May 30, 2020

Source: Routley. ${ }^{18}$

their potential exposure and the need to go into quarantine. This process often involved a "knock on the door" approach to actively find cases, a system that was highly effective and lauded by the World Health Organization (WHO). ${ }^{25}$

On the other hand, South Korea took a different route from Thailand in contact tracing. They employed the use of digital technology to control the spread by using global positioning system (GPS), tracking the use of credit cards, and checking closed-circuit television (CCTV) footage. The use of these sophisticated technologies enabled effective contact tracing to restrict the propagation of the virus. They also used a special application to access information about the total number of infected persons, areas involved, specific places positive patients had visited, and the contact history of such patients. This application gave an alert if one was within $10 \mathrm{KM}$ of an infected COVID-19 patient, thus ensuring adequate social distancing and preventing potential exposure. ${ }^{7}$

It is noteworthy that contact tracing, though an effective measure in controlling infection rate of the COVID-19 pandemic, may be a difficult feat in low and middle-income countries. As stated earlier, contact tracing requires the use of sophisticated technologies and it is usually effectively done by health workers. Countries with poor resources lack an efficient healthcare system, lack enough health personnel, are unable to deploy technological tools to trace contacts of a known case, and are closely-knitted. Thus, infection rates may go uncontrolled rapidly. The Indian government, for instance, launched and mandated the use of 'Aarogya Setu', a contact tracing app in early April to combat the spread of the infection. However, uptake of the app by residents was barely more than $10 \%$ since its launch and the country continues to experience a steady surge in the number of case. ${ }^{26}$ With an increasing number of cases, contact tracing becomes more difficult in India's densely populated cities. Like many other low and middle-income countries, India is yet to achieve a decline in the number of new cases. ${ }^{27}$ When contact tracing is done effectively, the attack rate of COVID-19 is expected to decline drastically. For example, a UK study found transmissibility of the virus to be reduced by $64 \%$ with manual tracing and $66 \%$ with the addition of app-based tracing. ${ }^{28}$ Reduction in attack rate helps to quickly flatten the curve of infectious diseases.

\section{TECHNOLOGY}

Technological innovations and advancement have proven to be important in public health and invariably in the fight in the ongoing COVID-19 pandemic. A key component to its success is the fact that less manpower is needed, therefore, overcoming the limitations of recruiting an infinite number of persons for tasks like contact tracing. ${ }^{29}$ Recent innovations like artificial intelligence (AI) which have been gaining a lot of momentum in recent years has helped to fast track the development of vaccines. It is also used to predict the best public health approach to diseases and helps in passing scientific information to the general public. ${ }^{30}$ For instance, on December 31, 2019, a Canadian AI driven algorithm platform called blue dot beat the American Centers for Disease Control and Prevention (CDC) and the WHO in announcing the outbreak of a strange pneumonia-like illness originating in Wuhan to its users. It took another one week for the CDC and WHO to inform the World. ${ }^{31}$ Another innovation is The Surveillance Outbreak Response Management and Analysis System (SORMAS), which was developed by German and Nigerian public health research 
institutions in conjunction with an international software company called Helmholtz Centre for Infection Research (HZI). They created an epidemiological tool that was initially developed for the Ebola outbreak but is now being used for COVID-19 across multiple countries. It provides real-time surveillance data that enables contact tracing, containment, and public health management of COVID-19 cases. ${ }^{32}$ Likewise, Singapore officially adopted a contact tracing app called "TraceTogether", which was made compulsory for its residents. The app uses Bluetooth technology to identify close contacts of patients who have been diagnosed with COVID-19.33

South Korea, which has been relatively successful so far in its battle against COVID-19, employed the use of Al to curb the transmission of the disease. As many as 9 in 10 South Koreans get alerts when they are close to a confirmed case. ${ }^{31}$ This was done using the "COVID-19 Smart Management System", an upgrade of a similar app used to fight the dreadful Middle Eastern Respiratory Syndrome(MERS) in 2015. ${ }^{33}$ In China, an AI algorithm claimed it could detect suspected cases in 20secs, about 45times faster than human detection, with 96 percent accuracy. Robots were used in Guangdong and Hubei provinces to deliver medications and necessities to in-patients or quarantined communities, effectively limiting direct contact and spread of the virus. ${ }^{31}$

Furthermore, teams of about 100 Spanish scientists are currently designing a software application that will utilize $\mathrm{AI}$ and Blockchain technology to make pandemic related projections and assist country-wide restriction measures. Blockchain technology would be used for the storage of digital identities and to assign certifications that would grant certain freedoms such as the clearance to go to work or a grocery store. Similarly, AI would use data from multiple sources including the news, journals, and healthcare collaborators to device predictive algorithms that can provide insights on the spread of the virus. This information would then be shared with healthcare professionals and the government. Many companies are already using Blockchain technology in the fight against COVID-19. A prime example is PricewaterhouseCoopers $(\mathrm{PwC})$ which has launched a masterpiece that allows real-time access to COVID-19 test results. A Canadian startup, Emerge, is launching a software called Civitas, to help local authorities around the world manage stay-at-home orders. ${ }^{34}$

\section{PUBLIC HEALTH EDUCATION AND TRAINING}

Health education is a key strategy to limit the spread of diseases and South Korea has been very aggressive and open in educating its masses about the COVID-19 pandemic. To educate and inform the people the government put up posters containing information on preventing transmission of the virus in public places. It released press statements periodically on television and the website of the Korean Center for Disease Control. ${ }^{7}$ Education also involves regular training of high-risk groups such as healthcare workers (HCWs). Optimal PPE preparedness is key to preventing infections among HCWs, it involves following strict PPE guidelines, regular training of HCWs, and appropriate response on transportation and admission of suspected cases. Although training on PPE usage, donning/doffing has been carried out in intensive care units (ICUs) worldwide, coaching for other aerosol-generating activities, such as tracheostomy procedures, non-invasive ventilation, sputum suctioning, etcetera, has been inconsistent. New Zealand was unrivaled in regular training for aerosol-generating activities. This reduced the spread of COVID-19 infections among HCWs compared to that seen in other countries and hence contributed to overall safety in the country. ${ }^{35}$

\section{HEALTHCARE}

The COVID-19 pandemic has revealed that most developed countries are struggling with their health care system. Respiratory failure is the leading cause of death from COVID-19, therefore, poor capacity to ventilate patients increases the case fatality rates. ${ }^{36}$ Countries like Germany have a robust healthcare system that contributed to its success in controlling the COVID-19 pandemic. Germany invests more on healthcare per capita than most other European countries. ${ }^{37}$ According to World Bank reports, it spends $\$ 4714.26$ per person each year. ${ }^{38}$ It is said to have the second most critical-care beds per capita in Europe. Germany has 621 beds per 100,000 people compared to Italy and Spain with 275 and 293 beds per 100,000 people respectively. ${ }^{39}$ Germany's success in flattening its COVID-19 curve is mainly credited to carrying out large numbers of testing and its investment in its health care system. South Korea, another country with an extensive healthcare system, is also one of the frontline countries to have successfully flattened its curve earlier on. South Korea's success is attributed to its experience with MERS in 2015. As a result, the country already had a sophisticated health system in place. 6 New Zealand also had an already existing strategy for respiratory infectious diseases as a result of influenza, therefore it was relatively easy to improve on this already existing strategy and implement it for COVID-19 elimination. ${ }^{40}$

Despite a high ranking in the healthcare system among European nations, Sweden suffered a huge blow to its health outcomes from the COVID19 pandemic. It was paradoxical to record the highest death rate per capita (36 per 100,000 people) in Europe in a country that boasts of strong public healthcare systems and low levels of health inequality. ${ }^{41}$ However, the country also approached the predicted health outcome of an increase in ICU bed requirement by 40 folds differently. Firstly, the public health department mandated voluntary self-isolation for symptomatic individuals and hospital admission limited to those with severe symptoms which reduced the ICU beds by five-folds. Secondly, the country doubled the number of available ICU beds. Thirdly, elderly patients with poor prognosis were not admitted to the ICU thereby reducing ICU load but potentially increasing death rates. ${ }^{42}$ Overall, the outcome measure of the effectiveness of a country's healthcare system in handling the pandemic is the mortality and morbidity rates reported.

\section{GOVERNMENT POLICIES}

Government policies are also helpful in controlling the pandemic. The New Zealand Government, to support its cit- 
izens and permanent residents during the unprecedented strict restriction, established a wage subsidy scheme that was made available for 3 months. Through this plan, residents who worked more than 20 hours in a week received 585.80 New Zealand dollars (US \$376.41) in compensation while those who typically worked for less than 20 hours got 350 dollars(US\$224.89) per week. ${ }^{43}$ This aided compliance to the lockdown and its overall success, as more residents had some degree of financial stability and understood the solemnity of the pandemic response. Also, the transparency of New Zealand's government imbued a level of "togetherness" against the virus not seen in most countries such that the ruling party engaged opposition party leaders, charging them with leading an epidemic response committee in which the meetings were streamed live. Decisions were made in collaboration with several stakeholders including business groups, scientific organizations, leaders, and health experts thus resulting in a sense of camaraderie. ${ }^{44}$ The Thai government from a policy standpoint issued price controls and actively monitored essential protective equipment like face masks and hand sanitizer gels ensuring their availability to the general public and regular usage. 13

Furthermore, the Chinese government extended the lunar New Year holiday to enable people to remain on lockdown. Residents of Hubei province who had already traveled elsewhere to celebrate the New Year before the ban on January 23 , were traced and kept under compulsory quarantine. Family members and contacts were all tested and monitored for symptoms. ${ }^{45}$

Finally, while most countries had put their residents in fear, likening the pandemic to war and battle, New Zealand has preached unity and calmness. Language was an important part of their strategy. They carefully explained what elimination meant in epidemiological terms. That it meant bringing the cases to zero or near zero and not necessarily the total absence of the disease. ${ }^{46}$

\section{RECOMMENDATIONS}

Countries are advised to invest widely and be creative in their testing strategies like South Korea did with its walkthrough and drive through testing booths. The importance of testing cannot be overemphasized in the management of a pandemic. Through extensive testing, especially if done early enough, more cases of the disease would be detected thereby limiting the spread of the virus. Testing should be carried out for both symptomatic and asymptomatic people as early as possible.

The use of technology is a promising area in public health as it seems to yield good results even though we have only just scratched the surface. If big technology and IT companies would pull resources to devise means to battle public health emergencies in the future, the world would be more prepared. We also encourage countries to invest in technology as it relates to public health. AI has shown its relevance in gathering much more data than we humans can, with the advantage of overcoming observer bias and remote operation. Digital health is invaluable in disease surveillance, screening, and monitoring of patients. Over 3 billion people, about 50 percent of the world's population, have smart phones. A highly untapped means of contact tracing, effecting social distancing, and health education, among other public health measures to curb a pandemic. However, there needs to be harmonization of all these interventions to enable a standard and effective means of fighting the pandemic.

Investing in the healthcare system clearly shows an advantage in battling the COVID-19 pandemic. Countries that invested more in their healthcare system experienced better outcomes compared to countries that were not as prepared. Specific emphasis should be placed on critical care beds, ICU training, and specific details on tackling aerosol-generating activities. A healthy healthcare workforce would increase the chances of successfully fighting the pandemic.

Well-targeted government policies are key to fighting the pandemic. Controlling the price of PPEs, ensuring the availability of ventilators in an organized manner to areas with the hardest hit, transparency by the government on the disease burden and progress with interventions, and above all preaching togetherness, not fear could foster a collective approach to fighting the pandemic and its overall success.

\section{CONCLUSIONS}

Although we cannot categorically say any measure is superior to the other, countries who have successfully combined multiple measures promptly, have recorded a relatively mild outbreak than countries who did not. All through history, pandemics have been recorded, for example, the bubonic plague and Spanish flu which killed millions of people in the 14th and early 20th century respectively. ${ }^{47}$ With the second wave of COVID-19 pandemic speculated for later this year, it is therefore imperative to be prepared to combat this worldwide nightmare which has caused thousands of lives and crippled the economy.

\section{Funding: None.}

Author's contributions: IF conceived the concept of the manuscript title, contributed to resource gathering, drafting, and editing. EU contributed to resource gathering, drafting, and editing. CO, IU and CA contributed to resource gathering and revising the manuscript for intellectual content. AA and UE contributed to editing and overall mentorship of the manuscript. All authors contributed to the refinement of the study and approved the final manuscript.

Competing interests: The author completed the Unified Competing Interest form at www.icmje.org/coi disclosure.pdf (available upon request from the corresponding author), and declare no conflicts of interest.

\section{Correspondence to:}

Dr. Iziegbe Fenemigho, M.B.B.S

Premier Specialists' Medical Center, 7 Ogalade Close, Victoria Island, Lagos. Nigeria izifenemigho@gmail.com 
This is an open-access article distributed under the terms of the Creative Commons Attribution 4.0 International License (CCBY-4.0). View this license's legal deed at http://creativecommons.org/licenses/by/4.0 and legal code at http://creativecommons.org/licenses/by/4.0/legalcode for more information. 


\section{REFERENCES}

1. World Health Organization. Coronavirus Disease (COVID-19) - events as they happen. https://www.wh o.int/emergencies/diseases/novel-coronavirus-2019/e vents-as-they-happen. Published 2020. Accessed June 7, 2020.

2. Johns Hopkins Coronavirus Resource Center. New Cases of COVID-19 in World Countries 2020. 2020. htt ps://coronavirus.jhu.edu/data/new-cases. Accessed May 26, 2020.

3. Gavin K. Flattening the Curve for COVID-19: What Does It Mean and How Can You Help? https:/healthb log.uofmhealth.org/wellness-prevention/flattening-c urve-for-COVID-19-what-does-it-mean-and-how-ca n-you-help. Accessed May 25, 2020.

4. Eubank S, Eckstrand I, Lewis B, Venkatramanan S, Marathe M, Barrett CL. Commentary on Ferguson, et al., "Impact of Non-pharmaceutical Interventions (NPIs) to Reduce COVID-19 Mortality and Healthcare Demand". Bull Math Biol. 2020;82(4):52. doi:10.1007/ s11538-020-00726-X

5. Vally H. 6 countries, 6 curves: How nations that moved fast against COVID-19 avoided disaster. 2020 . http://theconversation.com/6-countries-6-curves-ho w-nations-that-moved-fast-against-COVID-19-avoid ed-disaster-137333. Accessed May 28, 2020.

6. Wolfson E, Wilson C. Is the U.S. "Flattening the Curve?” See Daily Updates. 2020. https://time.com/58 09038/coronavirus-flatten-curve. Accessed June 7, 2020 .

7. Sari M. South Korea's Policy in Flattening the Curve on COVID-19 without Lockdown: A Lesson Learned. 2020. https://www.habibiecenter.or.id/img/publicatio n/4f9998ceb34c1270e8057cf8d973223f.pdf. Accessed May 30, 2020.

8. Choi S, Han C, Lee J, Kim S, Kim I. Innovative screening tests for COVID-19 in South Korea. Clinical and Experimental Emergency Medicine. 2020;7(2):73-77.

9. Ritchie H, Ortiz-Ospina E, Beltekian D, Mathieu E, Hasell J, Macdonald B, et al. Coronavirus (COVID-19) Testing - Statistics and Research. 2020. https://ourwo rldindata.org/coronavirus-testing. Accessed May 30, 2020 .

10. Center for Disease Control. The updates on COVID-19 in Korea. 2020. https://www.cdc.go.kr/boar d/board.es?mid=\&bid=0030. Accessed May 30, 2020.
11. Australian Government Department of Health. Chief Medical Officer's press conference about COVIDSafe and COVID-19. 2020. https://www.healt h.gov.au/news/chief-medical-officers-press-conferenc e-about-COVIDsafe-and-COVID-19-on-27-april-202 0. Accessed April 30, 2020.

12. Australian Government Department of Health. Total COVID-19 tests conducted and results. 2020. htt ps://www.health.gov.au/resources/total-COVID-19-te sts-conducted-and-results. Accessed April 22, 2020.

13. Statista. Latin America: COVID-19 tests by country. 2020. https://www.statista.com/statistics/11 05907/latin-america-coronavirus-COVID-19-tests-co untry/. Accessed May 30, 2020.

14. NZ Herald. COVID 19 coronavirus: PM Jacinda Ardern says virus is "currently eliminated" as NZ emerges from level 4.https://www.nzherald.co.nz/nz/ news/article.cfm?c id=1\&objectid=12327811. Published 2020. Accessed April 27, 2020.

15. Ministry of Health NZ. COVID-19 - current cases. 2020. https://www.health.govt.nz/our-work/diseasesand-conditions/COVID-19-novel-coronavirus/COVI D-19-current-situation/COVID-19-current-cases. Accessed June 7, 2020.

16. Chang H. An overview of United States travel restrictions due to the COVID-19 outbreak. 2020. http s://www.jdsupra.com/legalnews/an-overview-of-unite d-states-travel-77119/. Accessed May 27, 2020.

17. Aratani L, Miroff N. Passengers flying to the U.S. from 26 countries in Europe will face enhanced screening. Washington Post. https://www.washington post.com/transportation/2020/03/13/travelers-europ e-will-face-additional-scrutiny/. Published 2020. Accessed May 28, 2020.

18. Routley N. Infection Trajectory: See Which Countries are Flattening Their COVID-19 Curve. 2020. https://www.visualcapitalist.com/infection-traj ectory-flattening-the-COVID19-curve/. Accessed June $1,2020$.

19. The Civil Aviation Authority of Thailand (CAAT). Public Announcement Archives. https://www.caat.o r.th/en/archives/category/news-events-en. Published 2020. Accessed May 20, 2020. 
20. Shalini N. Sweden had one of the most relaxed COVID-19 lockdowns in the world. There's growing evidence that it helped it weather 2020's economic storm better than anywhere else. Business Insider. 2020. https://markets.businessinsider.com/news/stoc ks/sweden-coronavirus-economy-relaxed-lockdown-s tronger-rest-of-europe-2020-7-1029415101\#. Accessed July 22, 2020.

21. Goodman P. Sweden Has Become the World's Cautionary Tale. New York Times. https://www.nytim es.com/2020/07/07/business/sweden-economy-coron avirus.html. Published 2020. Accessed July 23, 2020.

22. Gronholt-Pedersen J, Skydsgaard N. Fast in, first out: Denmark leads lockdown exit. Reuters. https://w ww.reuters.com/article/us-health-coronavirus-denma $\underline{\mathrm{rk} / \text { fast-in-first-out-denmark-leads-lockdown-exit-idU }}$ SKBN22U1TC. Published 2020. Accessed July 23, 2020.

23. Ghosal S, Bhattacharyya R, Majumder M. Impact of complete lockdown on total infection and death rates: A hierarchical cluster analysis. Diabetes \& Metabolic Syndrome: Clinical Research \& Reviews. 2020;14(4):707-711.

24. Centers for Disease Control and Prevention. Case Investigation and Contact Tracing: Part of a Multipronged Approach to Fight the COVID-19 Pandemic. 2020. https://www.cdc.gov/coronavirus/20 19-ncov/php/principles-contact-tracing.html. Accessed April 2020.

25. Lim WS, Liang CK, Assantachai P, Auyeung TW, Kang L, Lee WJ, et al. COVID - 19 and older people in Asia: Asian Working Group for Sarcopenia calls to actions. Geriatrics \& Gerontology International. 2020;20(6):547-558.

26. Saikia A. COVID-19: As cases surge in India, most states abandon contact tracing. 2020. https://scroll.i n/article/967223/COVID-19-as-cases-surge-in-indiamost-states-abandon-contact-tracing. Accessed July 23, 2020.

27. Pamposh R. Problems Follow India's Virus Tracing App. U.S. News and World Report. https://www.usnew s.com/news/best-countries/articles/2020-06-08/india s-poor-left-out-by-governments-coronavirus-contac t-tracing-app. Published 2020. Accessed July 23, 2020.

28. Kucharski AJ, Klepac P, Conlan A, et al. Effectiveness of isolation, testing, contact tracing and physical distancing on reducing transmission of SARS-CoV-2 in different settings. medRxiv. 2020. do $\mathrm{i}: 10.1101 / 2020.04 .23 .20077024 \mathrm{v} 1$

29. Brownstein JS, Freifeld CC, Madoff LC. Digital Disease Detection - Harnessing the Web for Public Health Surveillance. New England Journal of Medicine. 2009;360(21):2153-2157.
30. UNESCO. Fighting COVID-19 through digital innovation and transformation. 2020. https://en.unes co.org/COVID19/communicationinformationrespons e/digitalinnovation. Accessed May 30, 2020.

31. Lee K-F. COVID-19 Will Accelerate the AI Health Care Revolution. Wired. 2020. https://www.wired.co $\mathrm{m} /$ story/COVID-19-will-accelerate-ai-health-care-rev olution/. Accessed May 29, 2020.

32. Official Website of Surveillance Outbreak Response Management \& Analysis System (SORMAS). https://sormasorg.helmholtz-hzi.de/. Accessed May 28, 2020.

33. Al Dahdah M, Alam MJ. Tracing Apps to Fight COVID-19. 2020. https://booksandideas.net/TracingApps-to-Fight-COVID-19.html. Accessed May 22, 2020.

34. Mapperson J. Spanish Researchers Try to "Flatten the Curve" with Blockchain App. Coin Telegraph. 2020. https://cointelegraph.com/news/spanish-resear chers-try-to-flatten-the-curve-with-blockchain-app. Accessed May 15, 2020.

35. Rajamani A, Subramaniam A, Shekar K, Haji J, Luo J, Bihari S, et al. Variations in Personal Protective Equipment Preparedness in Intensive Care Units during the COVID-19 Pandemic: A Survey of AsiaPacific Countries. medRxiv. 2020. doi:10.1101/2020.0 $\underline{5.06 .20093724 \mathrm{v} 1}$

36. Macintyre R, Heslop DJ. Public health, health systems and palliation planning for COVID - 19 on an exponential timeline. Medical Journal of Australia. 2020;212(10):440. doi:10.5694/mja2.50592

37. Bostock B. Germany is reopening with one of the lowest death rates in the world. Here's how it barely missed a trick as it fought the coronavirus. Business Insider. 2020. https://www.businessinsider.com/coron avirus-germany-reopening-low-deaths-testing-lockd own-2020-5. Accessed June 3, 2020.

38. World Bank. Current health expenditure per capita (current US\$). 2020. https://data.worldbank.or g/indicator/SH.XPD.CHEX.PC.CD?most recent valu e_desc=true. Accessed May 27, 2020.

39. World Health Organization. European health information at your fingertips. https://gateway.euro.w ho.int/en/hfa-explorer/. Accessed June 2, 2020.

40. Baker MG, Kvalsvig A, Verrall AJ, Telfar-Barnard L, Wilson N. New Zealand's elimination strategy for the COVID-19 pandemic and what is required to make it work. 2020. https://www.nzma.org.nz/journal-article s/new-zealands-elimination-strategy-for-the-COVI D-19-pandemic-and-what-is-required-to-make-it-wo rk. Accessed May 28, 2020. 
41. Barney J. Lack of COVID-19 Lockdown Increased Deaths in Sweden, Analysis Concludes. 2020. http s://news.virginia.edu/content/lack-COVID-19-lockdo wn-increased-deaths-sweden-analysis-concludes. Accessed July 23, 2020.

42. Kamerlin S, Kasson P. Managing COVID-19 spread with voluntary public-health measures: Sweden as a case study for pandemic control. Clinical Infectious Diseases. July 2020. doi:10.1093/cid/ciaa864

43. Employment New Zealand. COVID-19 Leave Support Scheme. https://www.employment.govt.nz/le ave-and-holidays/other-types-of-leave/coronavirus-w orkplace/leave-support-scheme/. Published 2020. Accessed May 25, 2020.
44. Duncan D. COVID-19 and Labour Law: New Zealand. Italian Labour Law e-Journal. Italian Labour Law e-Journal. 2020;13(Special Issue 1).

45. Chen S, Yang J, Yang W, Wang C, Bärnighausen T. COVID-19 control in China during mass population movements at New Year. The Lancet. 2020;395(10226):764-766.

46. Cousins S. New Zealand eliminates COVID-19. The Lancet. 2020;395(10235):1474. doi:10.1016/s014 $\underline{0-6736(20) 31097-7}$

47. Billings M. The Influenza Pandemic of 1918. http s://virus.stanford.edu/uda/. Accessed May 31, 2020. 